\title{
Inclusive Practices in Response \\ to the German Refugee Influx: Support \\ Structures and Rationales Described \\ by University Administrators
}

\author{
Lisa Unangst and Bernhard Streitwieser
}

\section{Introduction}

New and rapidly evolving challenges in the German post-secondary ecosystem have followed the recent influx of refugees from the Middle East, North Africa and beyond. Actors in the public, private, and community-based sectors alike have contributed resources and initiated programs seeking to address some of these challenges and capitalize on opportunities (for example, utilizing MOOCs in new and innovative ways). However, it is the 16 federal states that are primarily responsible for setting the higher education policy, and indeed, public universities are the primary providers of post-secondary education in Germany. Thus, policies set by the states are mediated both by federal government structures and supportsGerman Academic Exchange Service (or DAAD) funding serving as a good example - as well as by institutional priorities. Indeed, the influx of refugees to Germany and significant shifts in higher education policy make this a timely human rights issue with broad impact. As Kogan, Gebel, and Noelke write, "understanding how different education systems generate or mitigate social inequalities in education is a central aim of social stratification research" (Kogan et al. 2011, p. 70). Refugees in the German context encounter distinct supports and barriers in accessing higher education.

This paper highlights the support systems developed by 12 German universities for refugee students, probing these structures through two separate interview-based studies conducted by the authors and targeting university faculty and staff. With an

\author{
L. Unangst $(\bowtie)$ \\ Boston College, Chestnut Hill, USA \\ e-mail: unangstl@bc.edu \\ B. Streitwieser \\ George Washington University, Washington, D.C., USA \\ e-mail: streitwieser@email.gwu.edu
}

(C) The Author(s) 2018

A. Curaj et al. (eds.), European Higher Education Area: The Impact of Past and Future Policies, https://doi.org/10.1007/978-3-319-77407-7_18 
eye toward informing both practitioners and academics in the field, this paper presents data and seeks to encourage change at the institutional level, enabling understanding for and direct support of refugee student populations. We also seek to identify emerging best practices, particularly with practitioners in mind.

\section{Background}

As asylum-seekers and refugee numbers in Europe swelled from 2014 to 2015, German Chancellor Merkel took the rather remarkable step of committing significant resources to the support of unregistered refugees, issuing a call to action enshrined in the now famous phrase, "Wir Schaffen Das" ("We will manage it"). "In September 2015, Berlin pledged 6 billion euros ( $\$ 6.6$ billion) to support the 800,000 migrants - about quadruple the number from 2014-it was expecting to receive by the end of 2015" (Park 2015). However, initial optimism about taking a lead role in the refugee crisis soon turned to doubt, in large part because the financial burden was (and remains) substantial, with many costs falling directly on towns and municipalities. Die Zeit has estimated that costs ranged among German cities between Euro 132 and Euro 1666 per refugee per month in Germany (Friedrichs and Malter 2016).

Higher education in Germany is tuition-free, for domestic as well as for most international students (though this will soon change for non-EU students in the states of Baden-Württemberg and Nordrhein-Westfalen), including refugees. Further, all students who complete the university entrance qualification known as the Abitur become eligible to enter any public institution. However, because there are more applicants than spaces, in many institutions (particularly in the more popular metropolitan centres like Berlin or Munich), only those with top grades will be admitted; the problem is further heightened in the most popular subject areas. Of particular concern is the area of medical studies which tends to apply the "numerus clausus" most strictly. Despite their asylum status, refugees do not generally receive differential treatment in admissions decisions and must compete with all international students. However, while admission is competitive, there is some anecdotal evidence to suggest that there may be an informal cap on the number of refugee students per program.

Broadly speaking, the recent refugee influx has spurred the creation and extension of a suite of services for refugees who seek to enter the university in Germany. These services include verifying higher education entrance credentials, ensuring German language competency through preparatory classes, offering buddy and mentoring programs, auditing classes, and providing additional guidance and individual consultations services. Three general types of support ease the path to refugee entrance to German higher education. First, if tangible credentials are unavailable (if a refugee had to flee without documentation), one's university entrance qualification, or Hochschulzugangsberechtigung, can be verified against the Anabin database ("Anerkennung und Bewertung ausländischer 
Bildungsnachweise") and then processed at the universities through the Uni-assist e.V. organisation, which is the credential service provider to universities. Second, the TestAS exam is available to verify scholastic aptitude through a centrally administered, standard examination. The test can be taken in numerous languages and is free of charge the first time it is taken. Third, verifying applicants' language proficiency, which for university study at the BA, MA or $\mathrm{PhD}$ level in Germany must be at a level $\mathrm{C} 1$ competency, may be completed via a number of widely available testing mechanisms.

\section{Theoretical Framework}

We ground our study of inclusive practices and institutional support for refugee students in Critical Theory to explicitly acknowledge the social, historical, economic and ideological forces that impact contemporary German universities as well as their faculty, staff, students, and community stakeholders. That is to say, we acknowledge the impact in Germany-and Western Europe more broadly - of unequal power structures in society at large, which are reflected in the university setting and necessarily influence the experience of both prospective and enrolled students. As Gutierrez-Rodriguez puts it,

universities reflect deeply entrenched social inequalities marked by class, race, disability and migration...Thus, universities reflect the inherent social inequalities within the nation state. When it comes to German and British state universities, what becomes apparent is the class and racial stratification of these institutions (Gutiérrez-Rodríguez 2016)

Critical Theory allows for both macro and micro level exploration, which works well in analysing narrative work: administrators, students and faculty alike have direct experiences that shed light on campus, area, and national phenomena, as well as on specific student support programs as they exist in the German context.

Further, in the mode of Solórzano et al., we situate our work within a transformative paradigm that emphasizes "the centrality of experiential knowledge" and encourages an intersectional approach, calling attention to the experiences of marginalized groups such as refugees (Solórzano et al. 2000, p. 63). Finally, we focus on the power dynamics of the university setting, which can be split in broad terms into de facto (in practice) and de jure (formalised) operations.

As noted by Hurtado, "Researchers who use a transformative lens are typically engaged in a research process that helps educators and students divest from inequality embedded in norms and structures to devise solutions for social and institutional change" (Hurtado 2015, p. 290). Indeed, researchers in this mode respond directly to Bourdieu's problematisation of the school-based "reproduction of existing power relations in society by privileging the cultural background of students of the dominant class" (Kanno and Varghese 2010, p. 313). That is, transformative research commits to offering prompt, practical solutions for disadvantaged or marginalized groups. Transformative work is critical, in our view, to an 
exploration of refugee issues; not only have students of colour, migrant and refugee students (distinct categories which may overlap) been traditionally marginalised in the post-secondary education sphere, but given massification, neo-liberalism, and immigration reform (which continue to produce structural changes), a closer examination of this sector is indicated (Heath et al. 2008; Kristen and Granato 2007).

\section{Methodology}

In developing their interview protocols, both authors structured open-ended items with prompts that allowed ample opportunity to delve deeply into issues and experiences when the interviewee allowed while still maintaining a neutral stance as a researcher. Participants in interview series A (conducted by Unangst) were all attached to public research universities in northern or central Germany, with an even distribution among large cities, a medium-sized city, and large towns, all of which are situated in former West Germany (Unangst 2017). All participants were recruited through personal outreach and interviewed for about sixty minutes in nine in-person and one Skype conversations. A standard interview protocol was employed, with questions addressing administrator/faculty background, experiences with refugee and migrant students over time, conceptions of diversity at their university, and institutional support for their programming areas.

Participants in interview series B (conducted by Streitwieser) came from three universities of applied sciences (Hochschulen) in Berlin (both former East and West) and were recruited by a well-networked senior administrator from one of the institutions. The data were collected over four days in January 2017 through a series of one hour-long interviews. Four university administrators charged with refugee integration and two groups of six refugees each in focus groups were interviewed, however, this paper focuses on the administrator interviews (an analysis of the refugee student data is currently being prepared for separate publication ${ }^{1}$ ). A standard interview protocol was used and questions addressed to administrators asked them to describe the situation of refugees seeking access to their university, what their main constraints and support were, how they feel the higher education sector is responding, what their motivations and goals were for working with this population, and what they expected the ramifications to be in the coming years (Table 1).

In reviewing interview transcripts, an open coding technique was utilized to identify main concepts emerging from participant insights and observations. Next, axial coding was performed to group concepts into "families" employing a critical

\footnotetext{
${ }^{1}$ Streitwieser, B. (in progress). Integration of Refugees into German Higher Education: Seeking Access to Berlin Universities. Chapter proposal accepted for inclusion in K. Magos \& M. Margaroni for a Special issue on "Refugees Education and Experience" in the Global Education Review, Volume 5, No. 4, November, 2018.
} 
Table 1 Demographic characteristics of interview participants, Series A and B

\begin{tabular}{|c|c|c|c|c|}
\hline Respondent & Number & Gender & $\begin{array}{l}\text { Migrant } \\
\text { background }\end{array}$ & University type \\
\hline Faculty & $\begin{array}{l}5 \text { (Series A) } \\
1 \text { (Series B) }\end{array}$ & $\begin{array}{l}2 \text { male, } 3 \text { female } \\
\text { (Series A); } 1 \\
\text { female (Series } \\
\text { B) }\end{array}$ & $\begin{array}{l}1 \text { faculty } \\
\text { (Series A) }\end{array}$ & $\begin{array}{l}\text { Research Universities } \\
\text { (Series A) }\end{array}$ \\
\hline Administrators & $\begin{array}{l}5 \text { (Series A) } \\
2 \text { (Series B) }\end{array}$ & $\begin{array}{l}3 \text { male, } 2 \text { female } \\
\text { (Series A) } \\
1 \text { male, } 1 \text { female } \\
\text { (Series B) }\end{array}$ & $\begin{array}{l}2 \text { administrators } \\
\text { (Series A) } \\
1 \text { paid student } \\
\text { administrative } \\
\text { assistant } \\
\text { (Series B) } \\
\end{array}$ & $\begin{array}{l}\text { Research Universities } \\
\text { (Series A) } \\
\text { Universities of Applied } \\
\text { sciences serving } \\
10,000+\text { students } \\
\text { (Series B) }\end{array}$ \\
\hline $\begin{array}{l}\text { German student } \\
\text { support }\end{array}$ & 3 (Series B) & $\begin{array}{l}2 \text { female, } 1 \text { male } \\
(\text { Series B) }\end{array}$ & 1 male & \\
\hline
\end{tabular}

Totals: 16

lens (Kaveh 2014). While, assuredly, additional coding might result in important findings, the main emphasis in this iteration of the analysis was to identify broad themes relevant to a comparative case study of refugee student support at German universities.

In the mode of Pugach and Goodman, this paper seeks to offer a transparent evaluation of the author's own positionalities, so as to provide important detail and nuance on the role of the researcher (Pugach and Goodman 2015). As a graduate student and tenure-track academic who have worked on questions surrounding educational policy relating to the education of migrant populations in Germany (Streitwieser et al. 2017a, b), the authors are both interested on a personal and professional level in equitable access and attainment. As a result, we view reporting in the popular media on the refugee influx and education as well as research literature with a particular, critical lens. As Kilbourn writes,

A fundamental assumption for any academic research is that the phenomena (data) that we wish to understand are filtered through a point of view (a theoretical perspective) - that is to say, it is assumed that there is no such thing as a value-free or unbiased or correct interpretation of an event. Interpretations are always filtered through one or more lenses or theoretical perspectives that we have for "seeing" (Kilbourn 2006, p. 545).

\section{Key Findings}

\section{German Language Proficiency as a Significant Barrier}

German is a difficult language, both grammatically and phonetically, and when it is used colloquially it is distinctly different from the way it is used in professional situations. Arguably, university-level German is the most complex version and 
learning the particular academic language (Fachsprache) is exceedingly difficult. To learn this level of German sufficiently to successfully understand lectures and to produce quality written work takes time. Administrators in Series B noted frequently in this regard that refugees face a particularly difficult challenge as they compete with often more linguistically familiar international students, who may have a much longer history and familiarity with the German language (for example a Dutch or a Russian student) than a newly arrived refugee. Fear of inadequacy in German can then translate into a stronger reluctance to attend lectures and ask questions, thus further hindering integration. As the Staff Coordinator of Refugee Affairs at one Berlin universities noted

\begin{abstract}
My goodness, it will not just take a few months but a few years. How are they supposed to get by with just a rudimentary understanding of the language?....If someone's been a foreign student in Germany for years, or maybe worked here as an Au pair, they pose significant competition to refugees, so language is really the main and first hurdle that they need to overcome.... I tell them the story of a Finnish student who also had a very hard time getting into a German university so they won't think it's just being made difficult for Syrian students.
\end{abstract}

Given that prospective students with a refugee background enter Germany with varying levels of German proficiency, the length of time to acquire even B1 level proficiency (required for applicants to the university pathway programs surveyed) may be substantial. Pathway programs are not credit-bearing programs, but rather span a range of language and orientation offerings, aiming to prepare students with a secondary-level leaving certificate to successfully enrol in a degree-granting university program. Not all students are familiar with this two-tiered system of study encountered by most refugees: as one interview participant in Series A put it, he spent a lot of time telling students "it's going to take longer to get into the university system and even to graduate from the university than they were expecting." As noted by one staffer, a language preparation program launched at his institution was meant to bridge two language levels (from B1 to C1) in five months (in its first iteration), and the time allocated was found to be insufficient. The program was subsequently extended to six months, and a proposal for the third iteration of the initiative outlines a course of one year in length.

Several authors have noted that the relatively high threshold of C1 German language proficiency - generally required to enter a German language university degree program - prevents refugee students from accessing credit-bearing study for some time. $\mathrm{C} 1$ level proficiency is defined by the Council of Europe's portal as follows:

[Student] can understand a wide range of demanding, longer texts, and recognise implicit meaning. Can express him/herself fluently and spontaneously without much obvious searching for expressions. Can use language flexibly and effectively for social, academic and professional purposes. Can produce clear, well-structured, detailed text on complex subjects, showing controlled use of organisational patterns, connectors and cohesive devices (Council of Europe 2017). 
Further, one interview participant in Series A highlighted the even higher language threshold for teaching training programs, which is set by the state at a $\mathrm{C} 2$ level.

In addition to these barriers to degree program entry, another difficulty identified by interview participants in Series A was in absorbing content knowledge concurrent with learning new academic vocabulary. One administrator reported that a degree-seeking student with C1-level German skills dropped out of their political science program for this very reason: "He took classes for the first six weeks and then he terminated his university program because, he said, the language barrier is so high" and went on to note that it was the Fachsprache (subject-specific language) that was the main difficulty. The student has since taken an internship in the field and plans to re-apply in the future, after having acquired these subject-specific skills.

\section{Distinct Programs Offered in Distinct University Contexts}

The development of refugee support structures has varied widely by university. At one institution included in Interview Series A, an orientation program is limited to six-eight weeks, after which "people can go into the educational settings and find out if the educational system in Germany will suit their expectations" and then pursue being admitted as a degree-seeking student in the subject of their choice (once they meet language and secondary school leaving certificate requirements).

Further, it seems that the professional background of key constituents plays a critical role in how these programs evolve. Given the structure of primary financial support for most refugee programming, this is indeed logical: the DAAD's Integra program has funded a range of initiatives proposed by post-secondary institutions, which were developed to match university staff capacity and perceived current needs (Kanning 2017). For instance, one university staff member interviewed in Series A who has administered refugee programs since November 2016 noted that her prior experience working for the university played an important role in her current work. Building on a network of university, political, and community-wide contacts she had established over the previous years, she found it relatively easy to develop a range of seminars and modules which introduced refugee students enrolled in pathway programs to various academic specialties at the university, allowing them to consider whether they might like to study the topic more intensively. Further, she is responsible for continuing a pre-existing series of networking meetings for community stakeholders working on refugee issues. A Berlin university administrator interviewed in Series B spoke of how her prior experience living in Egypt and speaking Arabic had helped her to better understand some of the cultural nuances of refugee students from that region.

Another interview participant in Series A indicated that his university had launched programs supporting prospective refugee students in fall of 2015, after the city had received a swell of refugees in the summer of that year, and that it was very 
difficult to build upon the initial program offerings for the first academic year, given that offerings were closely tied to planned seminars and other academic offerings. This participant also noted the emphasis on the financing of education in his university's pathway program and provided an example of how critical this issue can be to students: a student who had attended several consultations with the university staff over summer months made the staffer aware that he was living in a tent, and as winter approached, his situation became more acute. The staffer himself estimated that he had spoken with over twelve agencies in the area trying to assist the student with financing and housing, and that this experience (while extreme) highlighted how difficult the process of resettlement can be for refugee students. The staffer reported, "we had to get in contact with a dozen... even more different institutions, which all said 'ok, you have a problem, we know that problem, and we would be responsible, but we cannot help because first of all you have to go there, and then you have to go there [to different offices]." He ended by saying that "that was so striking for me...how hard it was for $u s$ even to get clear information, to get clear direction... it must be really, really hard for people that don't know the system, that don't know the language... that don't even have a place where they can rest."

An additional Series A participant, a faculty member, noted that her university had offered to host refugees on the university campus itself at the beginning of the refugee influx and then convened a task force comprised of various university stakeholders to identify areas in which the institution could support prospective refugee students. She observed that she was not clear on whether students from a refugee background received, for instance, extra time for exams, which would be made available to other students who qualified for a "Nachteilsausgleich" (accommodations), but that she was in support of such an initiative.

\section{"Success" in Refugee Support Programming Is Opaque and Inconsistent}

Though how "success" was measured at the respective institutions was not a question explicitly addressed in either interview series, this emerged as a clear theme given a lack of data on student participation, lack of benchmarking practices, uncertainty regarding future funding, and lack of a clear mission or vision at the institutional level. In part, this difficulty measuring success via longitudinal evaluation is hampered by Germany's very strict data protection laws (Datenschutz), which make student tracking particularly challenging. These laws, which are even more restrictive than the Family Education Rights and Privacy Act (FERPA) regulations in the United States, do not allow for tracking of students with refugee backgrounds (Fluechtlingshintergrund), meaning that, as these individuals are mainstreamed into universities as regularly matriculated students, it becomes difficult to track whether they persist or drop out at proportionally higher rates than other international students. Universities, as a result, may only be able to anecdotally document the longer-term success of their refugee students after matriculation. 
Additionally, data are lacking on several levels: first, almost all interview participants noted that their institution had had very little idea how many refugee students to expect when programming was launched, and many noted that this was still the case. For some universities, most of the students served to date arrived on campus in 2015, while for others, 2017 represented a year of significant growth in refugee student engagement. One interview participant in Series A noted that his institution enrolled 30 language program participants in the summer semester of 2015, and by summer 2017, 330 students were enrolled in at least one program at the same site. Another staffer noted that their program launched in October 2016, when they had "no idea what the needs of the people participating in the program would be" and that they "developed the program on the fly." Only recently, he said, had they been able to plan ahead and proactively "plan solutions" for students, almost two years after program implementation.

In 2016, the secretary general of the DAAD, Dorothea Rüland, made the estimate publicly that 30,000-50,000 refugees would be prepared-having overcome administrative hurdles and language requirements - to seek access to higher education in the next several years (Rüland 2016). Universities surveyed did not have a "target" number of refugee students that they would like to be serving though, as noted previously, some had capacity limits on the number of students they were able to serve. It must be noted that, while in 2015 close to one million new refugees $(890,000)$ entered Germany, by 2016 , due to an EU deal with Turkey and the closure of borders in transit countries, the refugee influx entering Germany had been reduced to 280,000 (Trines 2017). But even so, as one administrator in Series B interviews noted, German bureaucracy had been confronted with a major challenge. He noted, for example, that Berlin's state Office of Health and Social Affairs, known as LaGeSo for short (Landesamt für Gesundheit und Soziales) had had to hire 1000 additional workers with only three months of training, and yet empowered them with authority to make life-altering decisions about a refugees' right or not to stay or need to leave the country.

As this enormous administrative challenge has filtered down to the university sector, we may also consider how nation-wide system actors seek success in terms of matriculated, degree-seeking students from a refugee background. According to a study by the German Rectors Conference (HRK), as of 2017, 1140 refugees had become officially enrolled in university study in the country, a fivefold jump over six months earlier, and the numbers of those seeking guidance to enter university had doubled over the course of one semester. Does this increase demonstrate "success" for the DAAD? For the HRK?

Students, staff and faculty interviewed almost universally displayed a lack of knowledge of refugee support structures at other universities. None of them had a clear sense of the most successful universities in this area; they were not aware of the number of refugee students in pathway or degree programs of other universities. A student interviewed in Series B was the only participant to mention the recognition that DAAD offers to notable refugee support programs. The DAAD has a small-scale competition that highlights student-led university programs that support refugees and it also holds regional conferences to highlight successful programs in 
the area. However, apparently neither of these initiatives were known to the interviewees in Series A.

Indeed, it seems as if the DAAD as the primary funder of such programs would be the natural party to distribute this type of information. In any case, the lack of knowledge of the scope of institutional responses may demonstrate a lack of familiarity with best practices and, of course, this necessarily limits the construction of success in any given campus context.

Further, all institutions surveyed in both Series A and Series B noted uncertainty regarding future funding for refugee support programs. While defining concrete funding mechanisms was not a primary focus of this project, it seems that some universities dedicate more institutional funding to refugee-relevant programming, while others rely primarily on DAAD support, and still others seek a combination of institutional, DAAD, and state or federal level support. Naturally, a lack of clarity around the sustainability of programming impacts the scope of work attempted and additionally creates stress for staff and faculty who already feel overburdened by their workload and student needs.

Finally, while a few interview participants in Series A highlighted the direct involvement of their university's vice president or rector in refugee programming, it was primarily related to securing funding for Integra programs and not related to an overarching, long-term vision for refugee integration. That is to say, it does not seem that senior leadership level "talking points" have translated to the faculty and staff level on this topic. One exception is notable: a faculty member who also holds a senior administration appointment spoke at length about their goals for the institution as a whole around not only refugee integration but issues of diversity more broadly, including the integration of students from a migrant background. However, this individual noted repeatedly that university politics and power structures made change slower than might be optimal. To be fair, change management is a chronically vexing challenge for most large institutions, whether they are universities, businesses or any other type of enterprise. Several administrators in Series B, however, while generally pleased with the level of support from above, were quite proud of the level of support from below, namely from students stepping up to volunteer for refugee integration initiatives. For example, the "Welcome-Students Helping Refugees" program of the DAAD funds students offering refugees language programs and other training opportunities during the summer months.

Another issue worth contemplating is the substance, not just societally but also within the universities, of the oft-touted "Welcome Culture." While the German response from the highest levels of government down to the university level were clearly inspired by Chancellor Angela Merkel's inspiring "Wir schaffen das" mantra, it is fair debate whether the response was one of obligation and a desire to continue to rehabilitate the country's image, or a truly energetic movement to take up refugees and help them find their way throughout German society. Indeed, some of the student administrators interviewed in Series B questioned the intent of programs like the DAAD's Integra initiative; were programs developed by universities, they wondered, mainly because they were receiving monetary support from the DAAD and because other universities were establishing similar programs? 
Speculation on this topic varied among respondents and was dependent on individual circumstances. However, it appears that many of the current programs on offer were not well thought out or carefully targeted to meet the needs of the refugees themselves. One administrator in Series B, for example, found it highly problematic that refugees themselves had not (at least to that point) been asked yet through an evaluation study to assess the services they were receiving. For her, any claim of the program's success could therefore only be anecdotal and unreliable. The respondent also noted that any future survey including identifying information would likely prevent a refugee student from responding candidly. After all, as she noted, who will bite the hand that feeds you?

\section{Enabling Access for Women Refugees Is a Key Goal}

It seems clear that interview participants perceive women to comprise a minority of refugee students being served at their institutions. In the Series A interviews, one staff member noted that $14 \%$ of participants in refugee support programs at her institution were women and that the university was making an effort to consider measures such as combining child care with programmatic offerings in order to increase participation in this area. Notably, the staff member who highlighted this gap identified herself as having a background in gender studies. In Series B, the administrators also voiced their concerns over the small number of Muslim refugee women in language courses then going on to seek entrance into university study. In this regard, the administrators noted a struggle between, on the one hand, wanting to encourage a greater participation among these women while, at the same time, not seeking to step into unfamiliar cultural territory and offend established norms.

In terms of the refugee influx to Germany in 2015-16, roughly $30 \%$ were women. The term "Asylum Darwinism" has been used to characterize the lower number of women who fled their countries for the simple reason that the passage was more dangerous for them (Lebecher). Once arrived in Germany, women also faced additional dangers in refugee centres where bathrooms and showers were not separate and sexual violence has been a significant factor (Hertie School). Some women may also serve as caretakers for the family, which may include children as well as older parents and partners, potentially resulting in limited mobility and time to pursue university access. The research shows that refugee women are also more reluctant to seek out health counselling, and psychological counselling, again compounding why women may face greater internal and external challenges in finding the time, money, and support to even contemplate, let alone find their way into a university, and eventually into a program of studies (Hertie report). Likely as a result of this, so far a much smaller percentage of women than men appear to be accessing language and university content courses. This gender disparity in university access is of concern to administrators, who would like to understand better what women refugees need in order to be able to access university opportunities (RUB). 


\section{Gap Between Refugees Interested in Study and Those Succeeding to Enrol as Students}

Several interview participants in Series A reported that the number of enrolled, degree-seeking refugee students at their institutions in 2017 was lower than they had anticipated. Some interview participants went further, indicating that education officials had underestimated how difficult it would be for refugee students - even those with strong academic backgrounds - to access public higher education in Germany. One staffer noted that there are "large groups" of people who fulfil the "basic requirements" to get into university but don't attend "because there are so many barriers to get into the university" and that this gap between "formal" and "actual" access didn't allow for a "diverse student body." Indeed, another interview participant noted that he believed that in medicine, about 600 people applied for study places each year, though only about 15 places were available. One faculty member in Series B interviews spoke at length about having to temper refugees' expectations (Erwartungsmanagement). She noted that not only do universities need to provide information to interested refugees about possible pathways into the institution but must also be sensitive to the natural disappointment or even anger some are bound to feel if they are unable to access higher education.

While degree-seeking student numbers stemming from the refugee influx are low, enrolment in so-called pathway programs (which are housed at various so-called Studienkolleg locations and other sites) is relatively strong, with some universities serving several hundred students in this capacity. While pathway programs differ by site, all of those surveyed offer language instruction, as well as some version of orientation programming, which may include: introduction to library services, access to sports offerings, and research and writing tutorials specific to the German context. One interview participant in Series A noted that, while the pathway program located on the university campus itself was the most popular program in the (relatively rural) region, that program's enrolment was capped and, therefore, prospective students were often forced to enrol in pathway programs at different sites in the region-it would be interesting indeed to compare the university enrolment ratios of graduates of the on-campus and off-campus programs.

During another interview in Series A, a staff member at a second relatively rural university noted that in the previous year, there had been 120 applications for the university's pathway program and that 40 applicants had been accepted. The same interview participant noted their concern that pathway program students would enrol at other universities when qualified for admittance; there appeared to be a concern for return on investment, as well as perhaps an awareness that certain cities or regions within Germany are perceived as more welcoming to the refugee community. This also indicates a possible roadblock for students: a desire to move to a more welcoming area without the resources to do so. Indeed, in Germany's response to the current refugee influx (previous crises having been in the early 1990s during the Balkan crisis, before that a variety of less dramatic population 
spikes through the post-war guest worker programs, and most dramatically in 1945 as millions of expelled ethnic Germans retreated from Eastern Europe toward Germany), Merkel's government has instituted a program that works to distribute refugees throughout the country in an effort to avoid them congregating in cities and creating what has been referred to as "parallel societies" or "ethnic enclaves" for lack of a better term.

Several staffers in Series A indicated that students enrolled in pathway programs or individual workshops were side-tracked from pursuing a credit-bearing study at university due to mental trauma, health issues, and family crises caused by war, flight and displacement. One interview participant noted that a refugee student from North Africa had had ten family members die during an attempted Mediterranean crossing - indeed, it is not only maintaining mental health which may be a "distraction" from study, but also life outside the classroom which moves forward in sometimes unexpected and difficult ways. This is an area widely studied among first-generation college students in the United States as well as among ethnic minority students in Germany. Claudia Diehl and co-contributors in their research highlight the difficulties encountered in student housing for Turkish students (Diehl et al. 2013). Along similar lines, in the Series B interviews an administrator cautioned that since "Syrians will be here for years to come, we need to treat them as Bildungsinlaender, not Bildungsauslaender," or those who earned their university entrance qualification in Germany versus international students. In this, she implied that Germany has an obligation to successfully integrate refugees, dealing with a wide range of challenges including mental health, on the assumption that they will remain for many years or perhaps permanently.

\section{Conclusion}

While current refugee flows to Germany have abated significantly given current efforts at the federal level to curtail entry by creating "reception centres" in Africa (and elsewhere) and the EU agreement with Turkey alluded to above, refugees will continue to seek entry to higher education in the country, particularly as more and more attain $\mathrm{C} 1$ German language proficiency. This paper has outlined initial findings from two closely related interview series with university staff and faculty at twelve institutions in Germany. We find continued evidence that the $\mathrm{C} 1$ language proficiency requirement for entry to a degree program represents the most significant barrier to refugee students; that a wide range of diverse and uncoordinated programmatic offerings exist in distinct university contexts; that "success" in the context of refugee support programs is ill defined and poorly communicated so that it is difficult to assess how well program implementation has gone; that women are underrepresented in refugee support programs; and that a troubling gap persists between students interested in study and those enrolling as degree seeking students (as well as the related challenge of the transition from interest to actual enrolment in the face of stiff competition for few spots). 
Moving forward, as students from refugee backgrounds continue in pathway programs and enrol as degree-seeking students in larger numbers, it will be important to observe whether there are differences in student persistence rates at different universities. Several interview participants at one of the "new" universities founded in the 1960s noted in Series A that their campus already had a high degree of diversity in terms of socio-economic status and non-traditional student backgrounds, and indicated that they felt that this environment was relatively welcoming to those from a refugee background. Interviewees in Series B also expressed pride in the openness of their institutions to helping refugees. Campus diversity, among many other factors including state social supports; diversity of the community at large; cost of living, etc., will likely impact persistence for this vulnerable student population. One interview participant in Series A noted that he felt that the university at which he worked ought to "embrace diversity" and that it was "symbolic what we do here." Indeed, post-secondary education plays (most critically) a practical role in the integration of refugees, but also a symbolic one.

It is also important to note that Series A and Series B focused on research universities and Fachhochschulen, respectively. These two types of institutions have different structures, different student populations, and a plethora of other distinctions that should not be ignored. That is to say, while we seek to provide an outline of our combined findings - areas of overlap - in this paper, future research might productively probe support structures at each of these institutional types.

Lastly, we would like to emphasize the problematic lack of information sharing among the institutions surveyed in the research discussed here. Given that staff time and other resources are required in order for an effective exchange of best practices to take place, we urge that German post-secondary institutions explicitly support these practitioners. Further, we urge both state government actors and the DAAD to support this improved communication wherever possible. After all, when services to refugee students at one institution work well, sharing that success more widely may improve services for all, surely a worthwhile endeavour.

Acknowledgements Bernhard Streitwieser would like to thank the GWU UNESCO Chair in International Education for Development for supporting this study with seed funding.

\section{References}

Council of Europe. (2017). Common European Framework of Reference for Languages (CEFR): Global scale-Table 1 (CEFR 3.3): Common Reference Levels. Retrieved August 20, 2017, from www.coe.int/en/web/common-european-framework-reference-languages/table-1-cefr-3.3common-reference-levels-global-scale.

Diehl, C., Andorfer, V. A., Khoudja, Y., \& Krause, K. (2013). Not in my kitchen? Ethnic discrimination and discrimination intentions in shared housing among university students in Germany. Journal of Ethnic and Migration Studies, 39(10), 1679-1697. https://doi.org/10. 1080/1369183X.2013.833705. 
Friedrichs, J., \& Malter, B. (2016). Wie viel kosten die Flüchtlinge? Die Zeit. Retrieved from http://pdf.zeit.de/2016/21/fluechtling-kosten-haushalt-bundeslaender-unterbringung.pdf.

Gutiérrez-Rodríguez, E. (2016). Sensing dispossession: Women and gender studies between institutional racism and migration control policies in the neoliberal university. Women's Studies International Forum, 54, 167-177. https://doi.org/10.1016/j.wsif.2015.06.013.

Heath, A. F., Rothon, C., \& Kilpi, E. (2008). The second generation in Western Europe: Education, unemployment, and occupational attainment. Annual Review of Sociology, 34(1), 211-235. https://doi.org/10.1146/annurev.soc.34.040507.134728.

Hurtado, S. (2015). The transformative paradigm: Principles and challenges. In C. Boston Martinez-Aleman, B. Pusser \& E. M. Bensimon (Eds.), Critical approaches to the study of higher education: A practical introduction (pp. 285-307). Baltimore: Johns Hopkins University Press.

Kanning, S. (2017). IntegratiFunding programme: Integrating refugees in Degree Programmesng Refugees in Degree Programmes. Retrieved August 15, 2017, from https://www.daad.de/derdaad/fluechtlinge/infos/en/41996-funding-programme-integrating-refugees-in-degreeprogrammes-integra/.

Kanno, Y., \& Varghese, M. M. (2010). Immigrant and refugee ESL students' challenges to accessing four-year college education: From language policy to educational. Journal of Language, Identity, and Education, 9(2), 310-328. https://doi.org/10.1080/15348458.2010. 517693.

Kaveh, Y. (2014). Family language policy and heritage language maintenance: The case of one Iranian immigrant family in the United States. Chestnut Hill.

Kilbourn, B. (2006). The qualitative doctoral dissertation proposal. Teachers College Record, 108 (4), 529-576. https://doi.org/10.1111/j.1467-9620.2006.00660.x.

Kogan, I., Gebel, M., \& Noelke, C. (2011). Educational systems and inequalities in educational attainment in Central and Eastern European Countries. Studies of Transition States and Societies, 4(1), 69-84.

Kristen, C., \& Granato, N. (2007). The educational attainment of the second generation in Germany: Social origins and ethnic inequality. Ethnicities, 7(3), 343-366. https://doi.org/10. 1177/1468796807080233.

Park, J. (2015). Europe's migrant crisis-Council on Foreign Relations. Retrieved January 1, 2016, from http://www.cfr.org/refugees-and-the-displaced/europes-migration-crisis/p32874.

Pugach, M. R., \& Goodman, L. A. (2015). Low-income women's experiences in outpatient psychotherapy: A qualitative descriptive analysis. Counselling Psychology Quarterly, 28(4), 403-426. https://doi.org/10.1080/09515070.2015.1053434.

Rüland, D. (2016). Öffentliche Anhörung des Ausschusses für Bildung, Forschung, und Technikfolgenabschätzung des deutschen Bundestages am 24. February, 2016. Stellungnahme: Öffentliches Gespräch zum Thema "Bildung in der Einwanderungsgesellschaft." Deutscher Bundestag. [Public hearing by the committee for education, research and technology impact assessment of the German parliament. Public discussion on the theme of education in an immigration society.].

Solórzano, D., Ceja, M., \& Yosso, T. (2000). Critical race theory, racial microaggressions, and campus racial climate: The experiences of African American college students. Journal of Negro Education, 69(1/2), 60-73.

Streitwieser, B., Brück, L., Moody, R., \& Taylor, M. (2017a). The potential and reality of new refugees entering German higher education: The case of Berlin Institutions. Forthcoming in European Education: Issues and Studies, special issue on "internationalization in conflict-ridden societies and within migrant populations.".

Streitwieser, B., Miller-Idriss, C., \& de Wit, H. (2017b). Higher education's response to the European refugee crisis. In J. Gacel-Avila, E. Jones, N. Jooste, \& H. de Wit (Eds.), The 
globalization of internationalization: Emerging voices and perspectives in the series, internationalization in higher education. London: Routledge.

Trines, S. (2017). Lessons from Germany's refugee crisis: Integration, costs, and benefits. World Education News and Reviews. World Education Services. Retrieved May 2, 2017, from http:// wenr.wes.org/2017/05/lessons-germanys-refugee-crisis-integration-costs-benefits.

Unangst, L. (2017). Facilitating refugee and migrant access to German Universities (Unpublished manuscript). Chestnut Hill.

Open Access This chapter is licensed under the terms of the Creative Commons Attribution 4.0 International License (http://creativecommons.org/licenses/by/4.0/), which permits use, sharing, adaptation, distribution and reproduction in any medium or format, as long as you give appropriate credit to the original author(s) and the source, provide a link to the Creative Commons license and indicate if changes were made.

The images or other third party material in this chapter are included in the chapter's Creative Commons license, unless indicated otherwise in a credit line to the material. If material is not included in the chapter's Creative Commons license and your intended use is not permitted by statutory regulation or exceeds the permitted use, you will need to obtain permission directly from the copyright holder.

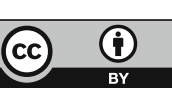

